Wilfrid Laurier University

Scholars Commons @ Laurier

Kinesiology and Physical Education Faculty

Publications

Kinesiology and Physical Education

2012

\title{
The Role of Medications in Predicting Activity Restriction Due to a Fear of Falling
}

Dawn M. Guthrie

Wilfrid Laurier University, dguthrie@wlu.ca

Paula C. Fletcher

Wilfrid Laurier University, pfletcher@wlu.ca

Evelyn Williams

Nicole Boumans

John P. Hirdes

University of Waterloo

Follow this and additional works at: https://scholars.wlu.ca/kppe_faculty

Part of the Health Services Research Commons

\section{Recommended Citation}

Guthrie DM, Fletcher PC, Berg K, Williams E, Boumans N, Hirdes JP. The role of medications in predicting activity restriction due to a fear of falling. Journal of Aging and Health 2012; 24:269-86

This Article is brought to you for free and open access by the Kinesiology and Physical Education at Scholars Commons@ Laurier. It has been accepted for inclusion in Kinesiology and Physical Education Faculty Publications by an authorized administrator of Scholars Commons @ Laurier. For more information, please contact scholarscommons@wlu.ca. 


\section{Journal of Aging and Health \\ http://jah.sagepub.com/}

\section{The Role of Medications in Predicting Activity Restriction Due to a}

Fear of Falling

Dawn M. Guthrie, Paula C. Fletcher, Katherine Berg, Evelyn Williams, Nicole Boumans and John P. Hirdes

J Aging Health published online 20 October 2011

DOI: $10.1177 / 0898264311422598$

The online version of this article can be found at:

http://jah.sagepub.com/content/early/2011/10/19/0898264311422598

Published by:

(9)SAGE

http://www.sagepublications.com

Additional services and information for Journal of Aging and Health can be found at:

Email Alerts: http:/jah.sagepub.com/cgi/alerts

Subscriptions: http://jah.sagepub.com/subscriptions

Reprints: http://www.sagepub.com/journalsReprints.nav

Permissions: http://www.sagepub.com/journalsPermissions.nav

>> Proof - Oct 20, 2011

What is This? 
The Role of

\section{Medications in}

Predicting Activity

Restriction Due to

a Fear of Falling
Journal of Aging and Health

$\mathrm{XX}(\mathrm{X}) \mathrm{I}-18$

(C) The Author(s) 2011

Reprints and permission: sagepub.com/journalsPermissions.nav

DOI: 10.1 | 77/08982643।|422598

http://jah.sagepub.com

๑SAGE

\author{
Dawn M. Guthrie, PhD', Paula C. Fletcher, PhD', \\ Katherine Berg, PT, PhD², Evelyn Williams, MD, \\ MHSc, CHE, FCFP ${ }^{2,3}$, Nicole Boumans, BSc', \\ and John P. Hirdes, PhD ${ }^{4,5}$
}

\begin{abstract}
Objectives: To examine the role of medication use and other factors in predicting activity restriction due to a fear of falling (AR/FF). Methods: Older adults were assessed twice with the interRAl Community Health Assessment and the Berg Balance Scale (BBS). The main outcome was limiting going outdoors due to an AR/FF. Medications were recorded by trained assessors. Results: Participants $(n=44 I)$ had a mean age of $80.3(S D=7.1)$ years, most were aged $65+(96.8 \%)$ and $29.3 \%$ reported activity restriction. Taking nervous system active or cardiovascular medications was associated with AR/FF. In a multivariate model, the main predictors were having $3+$ comorbid health conditions, lower (i.e., worse) scores on the BBS, having difficulty with climbing stairs, and having a visual impairment. Discussion: Modifiable risk factors, related to functional impairments, such as difficulties with balance and vision, appear to be more important predictors than medications.
\end{abstract}

\footnotetext{
'Wilfrid Laurier University, Waterloo, Ontario, Canada

${ }^{2}$ University of Toronto, Toronto, Ontario, Canada

${ }^{3}$ Sunnybrook Health Sciences Centre, Toronto, Ontario, Canada

${ }^{4}$ University of Waterloo, Waterloo, Ontario, Canada

${ }^{5}$ Homewood Health Centre, Guelph, Ontario, Canada
}

\title{
Corresponding Author:
}

Dawn M. Guthrie, Associate Professor, Dept. of Kinesiology and Physical Education,

Wilfrid Laurier University, Waterloo, ON, N2L 3C5

Email: dguthrie@wlu.ca 


\section{Keywords}

medications, geriatric assessment, mobility limitation

It is widely understood that falls in older adults (65+) have serious implications for their health, mortality, and quality of life. Having had a fall often leads to a fear of falling (FF) in this population (Scheffer, Schuurmans, van Dijk, van der Hooft, \& de Rooij, 2008). One potential consequence of a FF is activity restriction. Estimates of the prevalence of activity restriction due to a $\mathrm{FF}$ (hereafter referred to as "AR/FF") range from 19\% to 60\% (Curcio, Gomez, \& Reyes-Ortiz, 2009; Deshpande et al., 2008b; Fletcher \& Hirdes, 2004; Fletcher, Guthrie, Berg, \& Hirdes, 2010; Jang, Cho, Oh, Lee, \& Baik, 2007; Kempen, van Haastregt, McKee, Delbaere, \& Zijlstra, 2009; Murphy, Williams, \& Gill, 2002; Wilson et al., 2005; Zijlstra et al., 2007). This has important implications as $\mathrm{AR} / \mathrm{FF}$ is related to lower levels of performance in activities of daily living (ADLs; Curcio et al., 2009; Deshpande et al., 2008b), reduced mobility (Deshpande et al., 2008b), and falls (Curcio et al., 2009).

Several studies have examined different types of medications and the risk of falls in community-dwelling older adults. For example, the risk is increased among those taking benzodiazepines (BZDs; Ensrud et al., 2002; Leipzig, Cumming, \& Tinetti, 1999; Souchet, Lapeyre-Mestre, \& Montastruc, 2005), antidepressants (Kelly et al., 2003; Leipzig et al., 1999; Souchet et al., 2005), cardiac medications (Souchet et al., 2005), narcotics (Ensrud et al., 2002; Kelly et al., 2003), and anticonvulsants (Ensrud et al., 2002; Kelly et al., 2003).

Some medications have also been linked to an increased risk of fracture and other injuries. In particular, BZDs have been found to slightly increase the risk of femur fracture among nursing home residents(Sgadari et al., 2000) and to elevate the risk of various types of injuries, including fractures, sprains, strains, and contusions, among veterans attending an outpatient medical clinic (French, Campbell, Spehar, \& Angarn, 2005). Some research has also shown that older adults (aged 50+) taking a particular type of antidepressant, namely selective serotonin reuptake inhibitors (SSRIs), had twice the risk of experiencing a fragility fracture (e.g., fracture caused by minor trauma such as falling from a bed or a chair; Richards et al., 2007).

The literature linking falls and medication use has been limited by several methodological issues. For example, a recent systematic review identified that many studies have failed to explicitly outline how they define a "fall," medications have not been categorized using a standardized therapeutic classification system (e.g., Anatomical Therapeutic Chemical system developed by World Health Organization) and several confounding variables, such as 
age and sex, have been inadequately adjusted for in multivariate analyses (Hartikainen, Lonnroos, \& Louhivuori, 2007). Furthermore, some studies have failed to consider confounding by indication, which assesses the degree to which the risk of falls is related to underlying comorbid conditions as opposed to the therapeutic drug regimen (Daal \& van Lieshout, 2005). The presence of certain chronic health conditions may be more important than medication use as a risk for falling (Lawlor, Patel, \& Ebrahim, 2003).

Although it is well understood that certain medications increase the risk of falls, little is known about the use of medications and AR/FF. From a clinical point of view, it is conceivable that persons taking certain medications and experiencing more falls and/or symptoms that put them at risk of falling (e.g., dizziness) may limit their activities due to an AR/FF. Polypharmacy has been shown as an important risk factor (Curcio et al., 2009; Jang et al., 2007) and in one study; the risk was increased among those taking drugs to treat depression or anxiety (Austin, Devine, Dick, Prince, \& Bruce, 2007). It is not well understood whether certain classes of medications are independently associated with an increased risk of $\mathrm{AR} / \mathrm{FF}$ and how previous falls and other risk factors for falling influence this relationship.

The current article attempts to address several of the limitations in the current literature by assessing the unique contribution of different classes of medications, while taking into account important confounding variables, including the presence of various chronic health conditions, as they relate to $\mathrm{AR} / \mathrm{FF}$. We hypothesized that certain classes of medications, known to increase the risk of falling (e.g., BZDs, antidepressants), would increase the risk of AR/FF in this sample of community-dwelling older adults after controlling for other established risk factors for falling.

\section{Method}

The current project represents secondary analysis of data collected during five independent intervention studies on falls among older adults in the community. The methods have been described elsewhere (Fletcher, Berg, Dalby, \& Hirdes, 2009; Fletcher et al., 2010). Briefly, each of the sites were individually funded, set their own inclusion criteria, and determined the data collection procedures and instruments to be used. However, as part of the current project, each site was also required to collect additional assessments for each participant. The research teams from each site oversaw subject recruitment and all data submitted were stripped of unique identifiers. As such, additional ethics approval was not required for the analyses of combined data sets. 
Five sites recruited older adults (typically those aged 65+) for a falls intervention program. The nature of each program varied in intensity and approach. Some projects simply provided information to study participants whereas others offered a more intense and multifactoral intervention.

Research assistants (RAs) within each site were trained to complete an early version of the interRAI Community Health Assessment (CHA). This assessment tool was designed by interRAI (www.interrai.org), a not-for-profit research network, of more than 30 countries, whose focus is on the development and testing of assessment systems to improve the quality of life and delivery of services for vulnerable populations including older persons and persons with disabilities. The interRAI CHA captures basic demographic background as well as detailed information across 13 domains, including activities of daily (ADLs), instrumental ADLs, social functioning, mental health, and pain. In Ontario, interRAI assessment tools have been mandated by the provincial government in the home care sector, in complex continuing care facilities and phased implementation is currently ongoing in all longterm care homes.

Training in the use of the interRAI CHA was led by an experienced clinical educator affiliated with the University of Waterloo. The RAs were given detailed instructions for coding of each item as outlined in the training manual (Morris et al., 2006). Each participant was assessed twice, both prior to (baseline assessment) and following (reassessment) the site-specific intervention. The average time between assessments was 249.7 days $(S D=138.4)$.

\section{Measures}

The interRAI CHA contains approximately 150 items that represent a subset of the larger interRAI Home Care Instrument (Morris et al., 1999). The main dependent variable, activity restriction due to an AR/FF, was captured with a single dichotomous item: "Person limits going outdoors due to a fear of falling (e.g., stopped using bus, goes out only with others"; Morris et al., 2006).

Although not included in the core items on the interRAI CHA, two other questions were added and were taken verbatim from items include in the interRAI Home Care Instrument. One question assessed the person's ability to walk a quarter of a mile (about three blocks) and was coded from 0 (no difficulty) to 3 (completely unable). The second question rated their ability to navigate stairs and was coded as 0 (up and down stair without help), 1 (up and down stairs with help) or 2 (did not go up and down stairs).

A number of health subscales can be generated from the interRAI CHA. The Cognitive Performance Scale (CPS; Morris et al., 1994) ranges from 0 to 
6 (higher scores indicate greater cognitive impairment) and has been validated against the Mini-Mental State Examination (Hartmaier et al., 1995). The Depression Rating Scale (DRS) assesses depressive symptoms and a score of three or higher is typically used as a cut-off predictive of psychiatrist ratings and clinical thresholds used with the Hamilton and Cornell Scales (Martin et al., 2008). The Activities of Daily Living Self-performance Hierarchy Scale (ADL SHS) uses four ADL items and rates individuals from 0 to 6, with a higher score indicating a greater need for assistance. Its reliability and validity have been previously established (Morris, Fries, \& Morris, 1999). The Changes in Health End-stage Disease Signs and Symptoms (CHESS) scale was developed to detect health instability. Higher scores on the CHESS are associated with reduced survival over time (Armstrong, Stolee, Hirdes, \& Poss, 2010; Hirdes, Frijters, \& Teare, 2003). The Pain Scale uses two items to create a score that ranges from 0 (no pain) to 3 (severe daily pain) and has been shown to be highly predictive of pain on the Visual Analogue Scale in nursing home residents (Fries, Simon, Morris, Flodstrom, \& Bookstein, 2001).

Each person was also assessed with the Berg Balance Scale. This scale includes 14 items that represent typical daily activities (e.g., sitting, standing) and generates a score from 0 to 56, with a higher score indicating better performance. The scale has been previously validated in older individuals (Muir, Berg, Chesworth, \& Speechley, 2008).

Assessors recorded all medications taken within the previous week, including both prescription and over-the-counter preparations. The assessors were trained to use all information available to them, including reviewing the labels on pill bottles, asking the person or family member directly, and/or contacting the family physician or pharmacist as needed. The drug order date was not captured. Medications considered as risk factors for falling or AR/FF was coded into four mutually exclusive therapeutic classes: (a) nervous system active medications (e.g., benzodiazepines, antidepressants); (b) analgesics (e.g., nonopioid analgesics, including nonsteroidal antiinflammatory drugs, opioid analgesics); (c) cardiovascular medications (e.g., anticoagulants, antihypertensives); and (d) diuretics. These classes were based on a modification to the American Hospital Formulary System (American Society of Health-System Pharmacists, 2006) and coding of each drug was led by a physician (EW).

Participants taking at least one of the medications in a given category were included in that category (i.e., presence vs. absence of taking any drug within the category) regardless of the frequency or dose. The only exception was in the case of low dose aspirin (81 mg per day) which was coded as an 
anticoagulant (Category 3), and higher doses of aspirin, were included with analgesics (Category 2; nonopioid analgesic).

\section{Analysis}

Because of concerns about data quality, one site $(n=150)$ was removed prior to data analysis. The participants from this site were significantly more likely to be female $(92.4 \%$ vs. $67.1 \% ; p<.0001)$, to be divorced/widowed/never married $(17.4 \%$ vs. $7.4 \% ; p=.003)$, were less likely to report AR/FF $(12.9 \%$ vs. $30.1 \% ; p<.0001)$, and were significantly younger (mean age: 70.4 years vs. $79.5 ; p<.0001$ ). The final sample included 571 individuals, of whom, 441 (77.2\%) participants had nonmissing data for the main outcome on reassessment. The lack of outcome data on reassessment reflects the voluntary nature of the study and the fact that we had virtually no control over data collection and follow-up with study participants.

All explanatory variables and potential confounders were measured using the baseline assessment. The Pearson's chi-square test was used for categorical variables and the Student $t$-test for continuous variables to assess the bivariate (unadjusted) relationship between outcome variables, explanatory variables, and potential confounders. An alpha level of .05 (two-tailed) was used in all cases.

Multivariate logistic regression models were created to examine the influence of medication use after controlling for other potential explanatory variables. Variables considered as potential covariates included: age, sex, marital status, site, number and specific type of comorbid health conditions, Berg Balance Scale score, and scores on each of the CPS, DRS, ADL SHS, CHESS Scale, and Pain Scale, stair climbing, previous falls, poor self-rated health, dizziness, presence of environmental home hazards, vision impairment, ability to walk a quarter of a mile, loneliness, distress related to a decline in participation in social activities, the presence of any psychiatric diagnosis (single item), and each therapeutic class of drug. Specific subclasses of drugs (e.g., benzodiazepines) were only included if at least $10 \%$ of participants were taking these medications.

A variety of modeling techniques were used, including forward selection, backward elimination, and stepwise methods, to rule out order effects prior to specification of the final model. Only the covariates that were significantly related to the dependent measure $(p<.05)$ were examined in the multivariate models. Once the final multivariate model was specified, those candidate variables which had been significant at the bivariate level were then individually entered into the final model in order to assess whether they would remain 
significant or change the contribution of the existing covariates. This was done to eliminate the possibility of covariates being dropped from the model due to order effects in the stepwise procedures.

Logit plots were created for all continuous and ordinal variables and indicated that four covariates should be entered as discrete variables, namely, marital status, age, ADL SHS and number of health conditions. In the final model, all two-way interactions were considered but none were statistically significant. Multicollinearity in the final model was assessed using the variance inflation factor (VIF), whereby a score of 2.5 or higher was considered indicative of multicollinearity (Allison, 2001). All analyses were completed using SAS version 9.1 (SAS Institute Inc., 2001).

\section{Results}

Participants had a mean age of $80.3(S D=7.1)$ years, most were female $(66.4 \%)$ and just more than half $(50.1 \%)$ were married. Nearly $75 \%$ of participants were taking four or more different medications, $43.5 \%$ had an unsteady gait, and $31.2 \%$ limited going outdoors due to an AR/FF. Sites 3 and 4 recruited the majority of clients $(64.4 \%$; Table 1$)$.

Participants with AR/FF were significantly ( $p<.05$ in all cases) more likely to be taking multiple medications, to have three or more coexisting health conditions, to be experiencing unsteady gait, to have had two or more recent falls, to have a vision impairment, to being showing signs or symptoms of depression, to have ADL impairments, to have moderate to severe health instability, and to have moderate to severe pain. The study site was also significantly related to $\mathrm{AR} / \mathrm{FF}(p<.0001)$ with the prevalence ranging from 2.3 to $41.1 \%$ (Table 1 ).

The most prevalent type of medication used was cardiovascular medications $(66.9 \%)$, followed by analgesics $(51.7 \%)$, nervous system active (NSA) medications (30.8\%) and last, diuretics (11.1\%; Table 2). Individuals who reported $\mathrm{AR} / \mathrm{FF}$ were significantly more likely to be taking any NSA medication $(p=.003)$ or any cardiovascular medication $(p=.001)$. Individuals who were taking any type of NSA medication, any type of cardiovascular drug or any type of analgesic had a significantly lower (i.e., worse performance) score on the Berg Balance Scale ( $p<.05$ in all cases). Across the four classes of medications, age was a significant factor only for cardiovascular medications, such that those taking any of these drugs were significantly older than those who were not $(81.0$ years vs. $79.0 ; p<.001)$. Among those taking any NSA medications, they were significantly more likely to be female $(75.7 \% \mathrm{vs}$. $62.6 \% ; p=.007)$. Gender was nonsignificant across the other drug classes. 
Table I. Explanatory Variables and Demographic Characteristics of Study Participants $(n=44 \mathrm{I})$ by Activity Restriction Due to a Fear of Falling

\begin{tabular}{|c|c|c|c|c|}
\hline & \multicolumn{3}{|c|}{$\%(n)$} & \multirow[b]{2}{*}{$p$ value } \\
\hline & $\begin{array}{l}\text { Total sample } \\
(n=44 I)\end{array}$ & $\begin{array}{l}\text { No activity } \\
\text { restriction } \\
(n=3 \mid 2)\end{array}$ & $\begin{array}{l}\text { Activity } \\
\text { restriction } \\
(n=129)\end{array}$ & \\
\hline \multicolumn{5}{|l|}{ Age } \\
\hline Mean (SD) & $80.3(7.1)$ & 79.3 (7.I) & $82.8(6.3)$ & \\
\hline $18-64$ & $3.2(14)$ & $4.2(13)$ & $0.8(I)$ & .001 \\
\hline $65-74$ & I4.I (62) & $16.0(50)$ & $9.3(12)$ & \\
\hline $75-84$ & $59.6(263)$ & $61.2(191)$ & $55.8(72)$ & \\
\hline $85+$ & $23.1(102)$ & $18.6(58)$ & 34.1 (44) & \\
\hline Female & 66.7 (294) & $61.2(191)$ & $79.8(103)$ & .0002 \\
\hline \multicolumn{5}{|l|}{ Marital status } \\
\hline Married & 49.7 (219) & $58.0(181)$ & $29.5(38)$ & $<.0001$ \\
\hline Widowed & $42.6(188)$ & $33.3(104)$ & $65.1(84)$ & \\
\hline Other & 7.7 (34) & 8.7 (27) & $5.4(7)$ & \\
\hline \multicolumn{5}{|l|}{ Site } \\
\hline One & $15.0(66)$ & 7.1 (22) & 34.1 (44) & $<.0001$ \\
\hline Two & $8.6(38)$ & II.2 (35) & $2.3(3)$ & \\
\hline Three & 39.2 (173) & $49.4(154)$ & 14.7 (19) & \\
\hline Four & $25.2(\mathrm{III})$ & $18.6(58)$ & 41.1 (53) & \\
\hline Five & $12.0(53)$ & $13.8(43)$ & $7.8(10)$ & \\
\hline \multicolumn{5}{|c|}{ Number of prescription medications } \\
\hline $0-3$ & $25.4(I I 2)$ & $29.2(91)$ & $16.3(2 \mid)$ & .005 \\
\hline $4+$ & 74.60 (329) & $70.83(22 I)$ & $83.72(108)$ & \\
\hline \multicolumn{5}{|c|}{ Number of health conditions } \\
\hline $0-2$ & $50.1(22 I)$ & $59.9(187)$ & $26.4(34)$ & $<.0001$ \\
\hline $3+$ & $49.9(220)$ & $40.1(125)$ & $73.6(95)$ & \\
\hline Unsteady gait & 43.5 (191) & $30.9(96)$ & $74.2(95)$ & $<.0001$ \\
\hline \multicolumn{5}{|c|}{ Number of falls } \\
\hline 0 & $70.0(308)$ & $74.6(232)$ & $58.9(76)$ & .0002 \\
\hline $\mathrm{I}$ & I7.7 (78) & $17.0(53)$ & $19.4(25)$ & \\
\hline $2+$ & $12.3(54)$ & $8.4(26)$ & $21.7(28)$ & \\
\hline \multicolumn{5}{|l|}{ Vision } \\
\hline Adequate & $80.7(355)$ & $87.5(272)$ & $64.3(83)$ & $<.0001$ \\
\hline Impaired & $19.3(85)$ & $12.5(39)$ & $35.7(46)$ & \\
\hline
\end{tabular}


Table I. (continued)

\begin{tabular}{|c|c|c|c|c|}
\hline & \multicolumn{3}{|c|}{$\%(n)$} & \multirow[b]{2}{*}{$p$ value } \\
\hline & $\begin{array}{l}\text { Total sample } \\
(n=44 I)\end{array}$ & $\begin{array}{l}\text { No activity } \\
\text { restriction } \\
(n=312)\end{array}$ & $\begin{array}{l}\text { Activity } \\
\text { restriction } \\
(n=129)\end{array}$ & \\
\hline \multicolumn{5}{|l|}{ Stair climbing } \\
\hline Manages stairs without help & $57.0(250)$ & $71.9(223)$ & $20.9(27)$ & \multirow[t]{3}{*}{$<.0001$} \\
\hline Manages stairs with help & $20.7(91)$ & $12.3(38)$ & $4 I . I(53)$ & \\
\hline Did not do stairs & $22.3(98)$ & $15.8(49)$ & $38.0(49)$ & \\
\hline $\begin{array}{l}\text { Presence of at least one home } \\
\text { hazard }\end{array}$ & $21.7(94)$ & $20.33(62)$ & $25.00(32)$ & .28 \\
\hline \multicolumn{5}{|c|}{ Distress related to a decline in social activities } \\
\hline Not distressed by decline & $87.5(385)$ & $92.3(287)$ & $76.0(98)$ & \multirow[t]{2}{*}{$<0.0001$} \\
\hline $\begin{array}{l}\text { Person is distressed by } \\
\text { decline }\end{array}$ & $12.5(55)$ & $7.7(24)$ & $24.0(31)$ & \\
\hline $\begin{array}{l}\text { Berg Balance Scale Score } \\
\text { Mean (SD) }\end{array}$ & $45.6(11.9)$ & $49.6(8.0)$ & $36.1(14.1)$ & $<0.0001$ \\
\hline \multicolumn{5}{|l|}{ CPS Score } \\
\hline No impairment & $95.9(419)$ & $97.4(300)$ & $92.3(119)$ & \multirow[t]{2}{*}{.013} \\
\hline At least mild impairment & $4.1(18)$ & $2.6(8)$ & $7.8(10)$ & \\
\hline \multicolumn{5}{|l|}{ DRS Score } \\
\hline $\begin{array}{l}\text { No signs/symptoms of } \\
\text { depression }\end{array}$ & $86.9(375)$ & $89.8(274)$ & 79.5 (101) & \multirow[t]{2}{*}{0.0039} \\
\hline $\begin{array}{l}\text { Signs/symptoms of } \\
\text { depression }\end{array}$ & $13.2(57)$ & $10.2(3 \mathrm{I})$ & $20.5(26)$ & \\
\hline \multicolumn{5}{|l|}{ Activities of daily living SHS } \\
\hline No impairment & $97.0(426)$ & $98.7(306)$ & $93.0(120)$ & \multirow[t]{2}{*}{.0014} \\
\hline At least mild impairment & $3.0(13)$ & I.3 (4) & $7.0(9)$ & \\
\hline \multicolumn{5}{|l|}{ CHESS Score } \\
\hline $\begin{array}{l}\text { None or mild health } \\
\text { instability }\end{array}$ & $79.9(325)$ & $86.3(25 \mathrm{I})$ & $63.8(74)$ & \multirow[t]{2}{*}{$<.0001$} \\
\hline $\begin{array}{l}\text { Moderate to severe health } \\
\text { instability }\end{array}$ & $20.2(82)$ & $13.8(40)$ & $36.2(42)$ & \\
\hline \multicolumn{5}{|l|}{ Pain Scale Score } \\
\hline None or mild pain & $56.6(249)$ & $64.3(200)$ & $38.0(49)$ & \multirow[t]{2}{*}{$<.0001$} \\
\hline Moderate to severe pain & $43.4(191)$ & $35.7(111)$ & $62.0(80)$ & \\
\hline
\end{tabular}

Participants taking any NSA drug were also significantly more likely to have multiple falls in the previous 90 days $(17.7 \%$ vs. $9.9 \% ; p=.0006)$. Previous falls was not related to the other classes of medications (data not shown). 
Table 2. Unadjusted Relationship of Therapeutic Drug Classes to Activity Restriction Due to a Fear of Falling

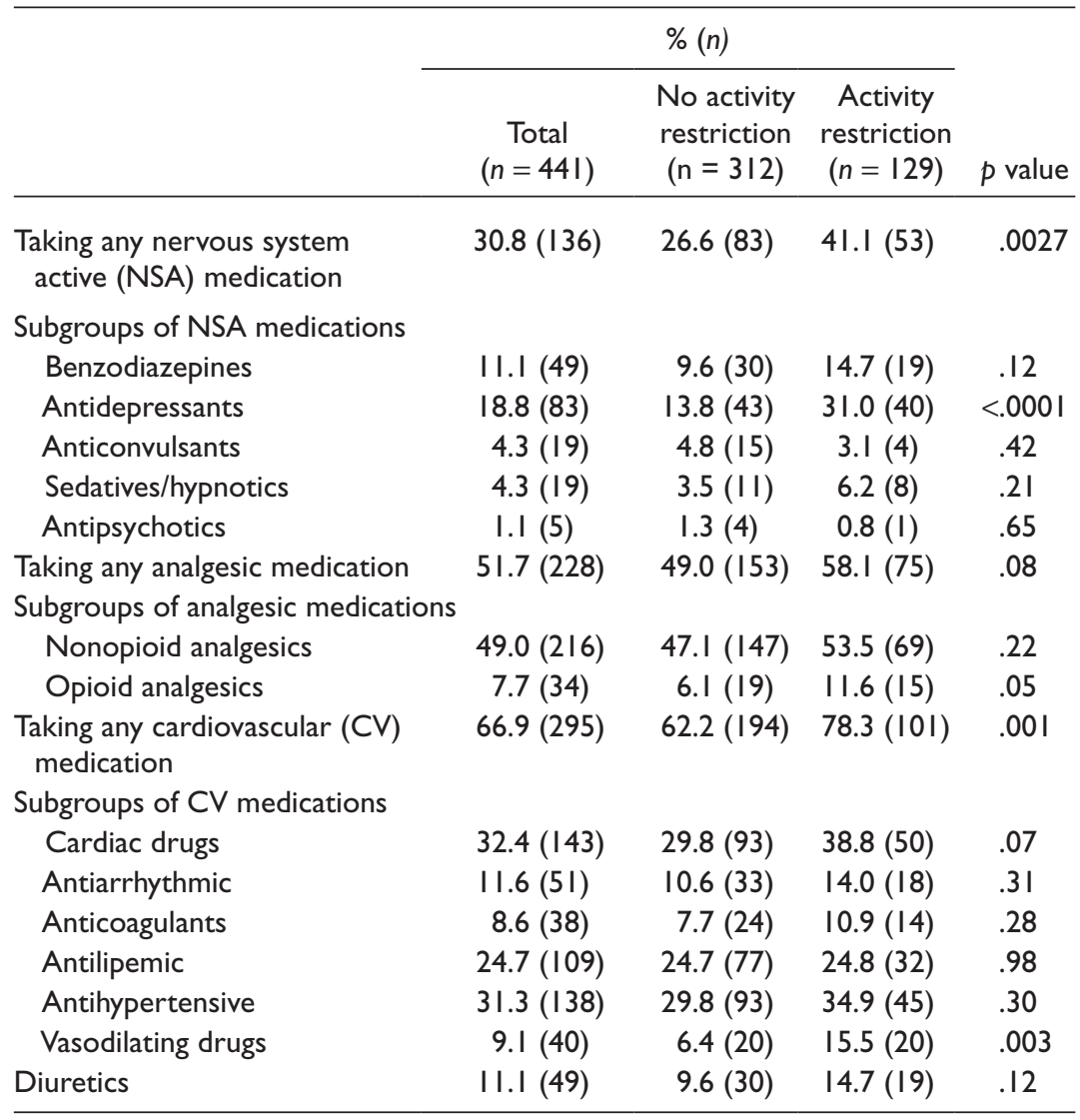

In a preliminary model (Model 1 in Table 3), several demographic characteristics were not significant predictors of $\mathrm{AR} / \mathrm{FF}$, including age, sex, and marital status. The same was found for the number of previous falls as well as each of the four therapeutic classes of medications. After adjusting for these variables, the covariates that were statistically important included: having three or more comorbid health conditions $(\mathrm{OR}=1.78)$, needing assistance with stairs $(\mathrm{OR}=3.52)$, the presence of a visual impairment $(1.87)$, and having a lower score on the Berg Balance Scale (0.73). In the final multivariate 
Table 3. Multivariate Models Predicting Activity Restriction Due to a Fear of Falling

\begin{tabular}{|c|c|c|c|c|}
\hline \multirow[b]{2}{*}{ Characteristics } & \multicolumn{2}{|c|}{ Model I ${ }^{\mathrm{a}}$} & \multicolumn{2}{|c|}{ Model $2^{b}$} \\
\hline & $\begin{array}{l}\text { Estimate (Std. } \\
\text { error) }\end{array}$ & $\begin{array}{l}\text { Adjusted odds } \\
\text { ratio }(95 \% \mathrm{Cl})\end{array}$ & $\begin{array}{l}\text { Estimate } \\
\text { (Std. Error) }\end{array}$ & $\begin{array}{l}\text { Adjusted odds } \\
\text { ratio }(95 \% \mathrm{Cl})\end{array}$ \\
\hline Age ( 10 year increase) & $0.028[0.02]$ & $1.32[0.82,2.09]$ & & \\
\hline Female & $0.30[0.33]$ & $1.35[0.71,2.59]$ & & \\
\hline \multicolumn{5}{|l|}{ Marital status } \\
\hline Married & Ref & Ref & & \\
\hline Widowed & $0.34[0.31]$ & $1.40[0.76,2.59]$ & & \\
\hline $\begin{array}{l}\text { Never married, } \\
\text { divorced, other }\end{array}$ & $-0.60[0.57]$ & $0.55[0.18,1.67]$ & & \\
\hline \multicolumn{5}{|l|}{ Number of falls } \\
\hline 0 & Ref & Ref & & \\
\hline I & $0.07[0.35]$ & $1.08[0.55,2.13]$ & & \\
\hline $2+$ & $0.15[0.38]$ & I. $16[0.55,2.58]$ & & \\
\hline \multicolumn{5}{|c|}{ Taking any nervous system active [NSA] medication } \\
\hline No & Ref & Ref & & \\
\hline Yes & $0.10[0.33]$ & $\mathrm{I} . \mathrm{II}[0.58,2 . \mathrm{II}]$ & & \\
\hline \multicolumn{5}{|c|}{ Taking any analgesic medication } \\
\hline No & Ref & Ref & & \\
\hline Yes & $0.12[0.27]$ & $1.12[0.66,1.92]$ & & \\
\hline \multicolumn{5}{|c|}{ Taking any cardiovascular $[\mathrm{CV}]$ medication } \\
\hline No & Ref & Ref & & \\
\hline Yes & $0.42[0.31]$ & $1.52[0.83,2.78]$ & & \\
\hline \multicolumn{5}{|l|}{ Taking any diuretic } \\
\hline No & Ref & Ref & & \\
\hline Yes & $0.39[0.45]$ & $\mathrm{I} .47[0.6 \mathrm{I}, 3.57]$ & & \\
\hline \multicolumn{5}{|c|}{ Number of comorbid health conditions } \\
\hline Zero to two & Ref & Ref & Ref & Ref \\
\hline Three or more & $0.58[0.29]$ & $1.78[1.01,3.13]$ & $0.74[0.28]$ & $2.09[1.22,3.59]$ \\
\hline \multicolumn{5}{|l|}{ Ability to climb stairs } \\
\hline No assistance required & Ref & Ref & Ref & Ref \\
\hline Stairs with assistance & $1.26[0.36]$ & $3.52[1.73,7.18]$ & I.38 $[0.34]$ & $3.96[2.04,7.72]$ \\
\hline Did not climb stairs & $0.79[0.37]$ & $2.21[1.07,4.58]$ & $1.03[0.35]$ & $2.80[1.18,3.84]$ \\
\hline $\begin{array}{l}\text { Presence of any visual } \\
\text { impairment }\end{array}$ & $0.64[0.32]$ & $1.87[1.0,3.50]$ & $0.75[0.3]$ & $2.04[1.11,3.76]$ \\
\hline $\begin{array}{c}\text { Five-point change on } \\
\text { Berg Balance Scale }\end{array}$ & $-0.06[0.01]$ & $0.73[0.63,0.83]$ & $-0.07[0.01]$ & $0.71[0.63,0.82]$ \\
\hline
\end{tabular}

a. Each adjusted OR was adjusted for the II other variables in the model; c statistic $=.86$

b. Parsimonious final model including the four variables that remained statistically significant $(p<.05)$; c statistic $=.85$. 
model, which included only these four significant covariates (Model 2), the odds ratios remained quite stable when compared to Model 1. The Hosmer and Lemeshow goodness-of-fit chi-square was not significant $(p=.73)$, suggesting an adequate fit of the model (Hosmer \& Lemeshow, 2000). Furthermore, the variance inflation factor was less than 1.75 in all cases, suggesting that multicollinearity was not present.

\section{Discussion}

In this project, $29 \%$ of adults limited their outdoor activities due to a fear of falling. This is consistent with other studies among community-dwelling seniors (Fletcher et al., 2010; Jang et al., 2007; Murphy et al., 2002; Zijlstra et al., 2007) and those receiving home care services (Fletcher \& Hirdes, 2004), but significantly lower than that reported in two previous studies (Curcio et al., 2009; Deshpande et al., 2008b). This is likely a reflection of the definition of activity restriction. This article used a more global definition of outdoor activities captured with a single question, whereas other research, reporting a higher prevalence, measured activity restriction across a number of specific activities (Deshpande et al., 2008b).

A key objective of this project was to assess the role of specific medications in predicting AR/FF. At the bivariate level, both central nervous system active (NSA) drugs and cardiovascular medications were important predictors. In addition, NSA drugs were related to an increased number of falls and three classes of medications, namely NSA drugs, cardiovascular drugs, and analgesics, were associated with worse performance on the Berg Balance Scale. Other research has shown an important role for antipsychotics (Fletcher $\&$ Hirdes, 2004) or for other NSA drugs to treat depression or anxiety (Austin et al., 2007) in the risk of AR/FF. However, after adjusting for other covariates, these classes of medications were nonsignificant. This may be due to the sample size of the study and the limited number of participants who were taking specific types of medications, such as antipsychotics. These results may also reflect the fact that medications, although associated with AR/FF, may have a more indirect effect through changes to one's risk of falling (e.g., through symptoms such as dizziness) that are difficult to detect without extensive longitudinal data that better map out the sequential changes that occur following the implementation of certain medications.

Our study confirms the importance of visual impairments (Curcio et al., 2009; Fletcher \& Hirdes, 2004; Murphy et al., 2002) and difficulties with balance (Deshpande et al., 2008b) as important independent predictors of AR/ FF. Requiring assistance in navigating stairs was also an important predictor 
and has not been reported in other studies. Having multiple coexisting health conditions was also important, and has been infrequently shown to be a risk factor in the literature (Murphy et al., 2002).

Depression has also been previously reported as a predictor of this outcome (Austin et al., 2007; Curcio et al., 2009; Deshpande et al., 2008a; Murphy et al., 2002). The current analysis also found, at the bivariate level, an increased likelihood of $\mathrm{AR} / \mathrm{FF}$ among clients with signs or symptoms of depression and among those taking antidepressant medications. The presence of symptoms of depression, however, was not important in the final multivariate model. The single item on the interRAI CHA indicates the presence of any psychiatric diagnosis, so we were unable to examine the diagnosis of depression on its own. However, given the high prevalence of the use of antidepressants (18\% in our sample), it is likely that depression was the main psychiatric diagnosis.

A decline in social activities, with perceived distress on the part of the person, was associated with the main outcome variable. Although measured somewhat differently, other studies have also found that measure of social isolation, such as living alone (Austin et al., 2007) or being alone for long periods of time in a day (Fletcher \& Hirdes, 2004) are associated with AR/FF. Given the fact that depression appears to be related to activity restriction, this suggests that AR/FF may be a key indicator of more global restrictions in one's activities. Activity restriction may reflect a process whereby older adults become more socially isolated and in turn, begin experiencing signs of depression. Alternatively, it may be that depression, and subsequent lack of motivation and/or lack of confidence, may lead to activity restriction.

One clear departure from the current evidence is the lack of an independent association between AR/FF and previous falls. Multiple studies have shown falls to be an important risk factor (Austin et al., 2007; Curcio et al., 2009; Fletcher \& Hirdes, 2004; Fletcher et al., 2010; Zijlstra et al., 2007) and only one did not (Jang et al., 2007). In the study by Murphy et al. (2002), only injurious falls were associated with activity restriction. We did, however, show falls to be important at the bivariate level but the item did not remain significant after adjusting for factors such as difficulties with navigating stairs and difficulties with balance.

Neither age nor sex was important, after adjusting for other important covariates. There are mixed findings in the current literature with some studies reporting older age as important (Kempen et al., 2009; Murphy et al., 2002; Zijlstra et al., 2007) and others, reporting a non-significant relationship (Austin et al., 2007; Jang et al., 2007). Being female has typically been seen to increase the risk of AR/FF (Fletcher \& Hirdes, 2004; Kempen et al., 2009; 
Murphy et al., 2002; Zijlstra et al., 2007). However, in at least one study, adjusting for $\mathrm{AR} / \mathrm{FF}$ removed the effect of gender on activity restriction, suggesting that fear was the key factor as opposed to being female per se (Deshpande et al., 2008a).

One limitation to this study is the fact that the participants represent a nonrandom convenience sample of volunteers. As such, it is likely that their risk profile, for falling and $\mathrm{AR} / \mathrm{FF}$, is different from the larger population of seniors in Ontario. This could, at least in part, explain the lack of consistency between this project and previous research, as it relates to risk factors such as age, sex, and previous falls.

Furthermore, we have chosen activity restriction, a behavioral outcome, as the main dependent variable. Although we can explore the relationship between activity restriction and a host of clinical and functional risk factors, the cross-sectional nature of the data do not allow for a full exploration of how medication use may lead to changes in symptoms related to falls, such as dizziness or unsteady gait, which may increase the risk of falls which, if a fall takes place, may then result in activity restriction. As such, the current findings cannot easily shed light on the causal pathway linking certain medications, and the diagnoses for which they were prescribed, with changes in psychosocial and behavioral outcomes. Future research using a prospective cohort design would be better able to address these limitations.

A longitudinal design would also be able to address the fact that the interRAI CHA does not include the date the medication was ordered. The crosssectional nature of this study makes it difficult to clearly determine cause and effect when looking at medication use. Given that the interRAI CHA is scheduled to be mandated for all community support services in Ontario, this type of analysis may soon be feasible.

The use of the interRAI CHA represents a significant strength of this project given its multidimensional nature and the fact that it will soon be the assessment of choice across the province. With data such as these, we have been able to study a broad range of covariates related not only to demographic characteristics but also to physical performance, functional status, and psychosocial factors. As has been demonstrated, understanding AR/FF is a complex issue that cannot be explained simply by looking at physical performance in areas such as vision, walking, or gait. There appears to be a psychosocial component related to social isolation and depression that should be explored further in a more rigorous study that includes a larger sample size than in the current project.

For clinicians, and those serving older adults in the community, understanding what contributes to activity restriction can have a positive effect 
on the quality of life and health of their clients. As we have shown, certain classes of medications (e.g., nervous system active and cardiovascular medications) are related, on their own, to AR/FF. However, there are other modifiable risk factors (e.g., impaired vision, difficulties with balance) that appear to be more important in predicting activity restriction due to an AR/ FF than medications. By recognizing how these modifiable factors may lead to activity restriction, which in turn may result in feelings of social isolation or depression, there is an important opportunity to identify seniors at risk early in this process. Early identification can ideally result in timely intervention. Given the importance of balance as a risk factor, prevention efforts should incorporate opportunities to increase capacity in areas such as balance, strength, and endurance.

If the appropriate programs and interventions are put into place that enable older adults to be more active, improve their balance, be less fearful and be engaged socially, there is the strong potential to reduce the likelihood of negative outcomes such as falling or developing an AR/FF.

\section{Acknowledgments}

The authors gratefully acknowledge Mr. Jeremiah Beggs for assistance with data analysis.

\section{Declaration of Conflicting Interests}

The authors declared no potential conflicts of interest with respect to the research, authorship, and/or publication of this article.

\section{Funding}

The authors disclosed receipt of the following financial support for the research, authorship, and/or publication of this article: This study was supported by the financial contribution from Veterans Affairs Canada- Falls Prevention Initiative, Health Canada. The views expressed herein do not necessarily represent the official policy of Health Canada or Veterans Affairs Canada. Dr. Hirdes' work was supported through the Ontario Home Care Research and Knowledge Exchange Chair award from the Ontario Ministry of Health and Long-Term Care.

\section{References}

Allison, P. D. (2001). Logistic regression using the SAS system: Theory and application. New York, NY: John Wiley.

American Society of Health-System Pharmacists. (2006). AHFS: Drug information. Bethesda, MD: American Society of Health-System Pharmacists. 
Armstrong, J. J., Stolee, P., Hirdes, J. P., \& Poss, J. W. (2010). Examining three frailty conceptualizations in their ability to predict negative outcomes for homecare clients. Age and Ageing, 39, 755-758.

Austin, N., Devine, A., Dick, I., Prince, R., \& Bruce, D. (2007). Fear of falling in older women: A longitudinal study of incidence, persistence, and predictors. Journal of American Geriatrics Society, 55, 1598-1603.

Curcio, C. L., Gomez, F., \& Reyes-Ortiz, C. A. (2009). Activity restriction related to fear of falling among older people in the Colombian Andes mountains: Are functional or psychosocial risk factors more important? Journal of Aging and Health, 21, 460-479.

Daal, J. O., \& van Lieshout, J. J. (2005). Falls and medications in the elderly. Netherlands Journal of Medicine, 63, 91-96.

Deshpande, N., Metter, E. J., Bandinelli, S., Lauretani, F., Windham, B. G., \& Ferrucci, L. (2008a). Psychological, physical, and sensory correlates of fear of falling and consequent activity restriction in the elderly: The InCHIANTI study. American Journal of Physical Medicine and Rehabilitation, 87, 354-362.

Deshpande, N., Metter, E. J., Lauretani, F., Bandinelli, S., Guralnik, J., \& Ferrucci, L. (2008b). Activity restriction induced by fear of falling and objective and subjective measures of physical function: A prospective cohort study. Journal of American Geriatrics Society, 56, 615-620.

Ensrud, K. E., Blackwell, T. L., Mangione, C. M., Bowman, P. J., Whooley, M. A., Bauer, D. C., . . . Nevitt, M. C. (2002). Central nervous system-active medications and risk for falls in older women. Journal of the American Geriatrics Society, 50, 1629-1637.

Fletcher, P. C., Berg, K., Dalby, D. M., \& Hirdes, J. P. (2009). Risk factors for falling among community-based seniors. Journal of Patient Safety, 5, 61-66.

Fletcher, P. C., Guthrie, D. M., Berg, K., \& Hirdes, J. P. (2010). Risk factors for restriction in activity associated with fear of falling among seniors within the community. Journal of Patient Safety, 6, 187-191.

Fletcher, P. C., \& Hirdes, J. P. (2004). Restriction in activity associated with fear of falling among community-based seniors using home care services. Age and Ageing, 33, 273-279.

French, D. D, Campbell, R., Spehar, A., \& Angarn, D. M (2005). Benzodiazepines and injury: A risk adjusted model. Pharmacoepidemiology and Drug Safety, 14, 17-24.

Fries, B. E., Simon, S. E., Morris, J. N., Flodstrom, C., \& Bookstein, F. L. (2001). Pain in US nursing homes: Validating a pain scale for the Minimum Data Set. Gerontologist, 41, 173-179. 
Hartikainen, S., Lonnroos, E., \& Louhivuori, K. (2007). Medication as a risk factor for falls: Critical systematic review. Journal of Gerontology: Medical Sciences, $62 \mathrm{~A}, 1172-1181$.

Hartmaier, S. L., Sloane, P. D., Guess, H. A., Koch, G. G., Mitchell, C. M., \& Phillips, C. D. (1995). Validation of the Minimum Data Set Cognitive Performance Scale: Agreement with the Mini-Mental State Examination. Journals of Gerontology.Series A, Biological Sciences and Medical Sciences, 50A, M128-M133.

Hirdes, J. P., Frijters, D. H., \& Teare, G. F. (2003). The MDS-CHESS Scale: A new measure to predict mortality in institutionalized older people. Journal of the American Geriatrics Society, 51, 96-100.

Hosmer, D. W., \& Lemeshow, S. (2000). Applied logistic regression (2nd ed.). Hoboken, NJ: John Wiley.

Jang, S. N., Cho, S. I., Oh, S. W., Lee, E. S., \& Baik, H. W. (2007). Time since falling and fear of falling among community-dwelling elderly. International Psychogeriatric Association, 19, 1072-1083.

Kelly, K. D., Pickett, W., Yiannakoulias, N., Rowe, B. H., Schopflocher, D. P., Svenson, L., \& Voaklander, D. C. (2003). Medication use and falls in community dwelling older persons. Age and Ageing, 32, 503-509.

Kempen, G. I., van Haastregt, J. C., McKee, K. J., Delbaere, K., \& Zijlstra, G. A. (2009). Socio-demographic, health-related and psychosocial correlates of fear of falling and avoidance of activity in community-living older persons who avoid activity due to fear of falling. BMC Public Health, 2, 170.

Lawlor, D. A., Patel, R., \& Ebrahim, S. (2003). Association between falls in elderly women and chronic diseases and drug use: Cross sectional study. British Medical Journal, 327, 712-717.

Leipzig, R. M., Cumming, R. G., \& Tinetti, M. E. (1999). Drugs and falls in older people: A systematic review and meta-analysis: I. psychotropic drugs. Journal of the American Geriatrics Society, 47, 30-39.

Martin, L., Poss, J. W., Hirdes, J. P., Jones, R. N., Stones, M. J., \& Fries, B. E. (2008). Predictors of a new depression diagnosis among older adults admitted to complex continuing care: Implications for the Depression Rating Scale (DRS). Age and Ageing, 37, 51-56.

Morris, J. N., Berg, K., Bjorkgren, M. A., Frijters, D., Fries, B. E., Gilgen, R., . . . Steel, K. (2006). InterRAI-Community Health Assessment (CHA). Guide for use of the interRAI CHA assessment form, Canadian version 07. Boston, MA: interRAI.

Morris, J. N., Fries, B. E., Bernabei, R., Steel, K., Ikegami, N., Carpenter, G. I.,. . . . Hirdes, J. P. (1999). RAI-Home Care (RAI-HC) assessment manual for Version 2.0. Washington, DC: interRAI. 
Morris, J. N., Fries, B. E., Mehr, D. R., Hawes, C., Mor, V., \& Lipsitz, L (1994). MDS Cognitive Performance Scale. Journals of Gerontology.Series A, Biological Sciences and Medical Sciences, 49, M174-M182.

Morris, J. N., Fries, B. E., \& Morris, S. A. (1999). Scaling ADLs within the MDS. Journals of Gerontology.Series A, Biological Sciences and Medical Sciences, 54A, M546-M553.

Muir, S. W., Berg, K., Chesworth, B., \& Speechley, M. (2008). Use of the Berg Balance Scale for predicting multiple falls in community-dwelling elderly people: A prospective study. Physical Therapy, 88, 449-459.

Murphy, S. L., Williams, C. S., \& Gill, T. M. (2002). Characteristics associated with fear of falling and activity restriction in community-living older persons. Journal of the American Geriatrics Society, 60, 516-520.

Richards, J. B, Papaioannou, A., Adachi, J. D, Joseph, L., Whitson, H. E, Prior, J. C., \& Goltzman, D. (2007). Effect of selective serotonin reuptake inhibitors on the risk of fracture. Archives of Internal Medicine, 167, 188-194.

SAS Institute Inc. (2001). The SAS System for Windows [Computer software]. Cary, NC: Author.

Scheffer, A. C., Schuurmans, M. J., van Dijk, N., van der Hooft, T., \& de Rooij, S. E. (2008). Fear of falling: Measurement strategy, prevalence, risk factors and consequences among older persons. Age and Ageing, 37, 19-24.

Sgadari A, Lapane KL, Mor, V., Landi F, Bernabei, R., \& Gambassi G (2000). Oxidative and nonoxidative benzodiazepines and the risk of femur fracture. The systematic assessment of geriatric drug use via Epidemiology Study Group. Journal of Clinical Psychopharmacology, 20, 234-239.

Souchet, E., Lapeyre-Mestre, M., \& Montastruc, J. L. (2005). Drug related falls: A study in the French Pharmacovigilance database. Pharmacoepidemiology and Drug Safety, 14, 11-16.

Wilson, M. G., Miller, D. K., Andresen E. M., Malmstrom T. K., Miller J. P., \& Wolinsky F. D. (2005). Fear of falling and related activity restriction among middle-aged African Americans. Journal of Gerontology: Medical Sciences, 60A, 355-360.

Zijlstra, G. A., van Haastregt, J. C., van Eijk, J. T., van Rossum, E., Stalenhoef, P. A., \& Kempen, G. I. (2007). Prevalence and correlates of fear of falling, and associated avoidance of activity in the general population of community-living older people. Age and Ageing, 36, 304-309. 